\title{
Erratum to: How the projection domains of NF-L and $\alpha$-internexin determine the conformations of NF-M and NF-H in neurofilaments
}

\author{
F. A. M. Leermakers $\cdot$ E. B. Zhulina
}

Published online: 20 April 2010

(C) European Biophysical Societies' Association 2010

\section{Erratum to: Eur Biophys J}

DOI 10.1007/s00249-010-0585-z

The last line before the Result section was published with errors. The corrected sentence is given here:
"In these calculations the total number of projections per unit length was fixed, $\Theta_{\mathrm{M}}=\Theta_{\mathrm{M}}^{\mathrm{W}}=60.48, \Theta_{\mathrm{H}}=$ $\Theta_{\mathrm{H}}^{\mathrm{W}}=48.56$, while $\Theta_{\mathrm{L}}$ and $\Theta_{\alpha}$ were varied."

The online version of the original article can be found under doi:10.1007/s00249-010-0585-z .

F. A. M. Leermakers $(\square)$

Laboratory of Physical Chemistry and Colloid Science,

Wageningen University, Dreijenplein 6,

6307 HB Wageningen, The Netherlands

e-mail: frans.leermakers@wur.nl

E. B. Zhulina

Institute of Macromolecular Compounds of the Russian

Academy of Sciences, 199004 St. Petersburg, Russia 